\title{
The Regulation of Erythropoiesis in the Suckling Rabbit
}

\author{
Karin Halvorsen ${ }^{[24]}$ and Sverre Halvorsen \\ Pediatric Department, Ullevål Hospital and Pediatric Research Institute, Barneklinikken, Rikshospitalet, Oslo, Norway
}

\begin{abstract}
Extract
The erythropoietin (ESF) and erythrocyte production after hypoxia and the role of iron in the erythropoietic response to hypoxia were studied in suckling rabbits. There was no spontaneous increase in plasma ESF levels before weaning in spite of a marked "early anemia." After both bleeding and hypoxia, ESF in plasma rose significantly also during the suckling period. Hypoxia increased total erythrocyte volume (RCV) only slightly in suckling rabbits without iron supplementation. Iron supplementation increased $\mathrm{RCV}$, hematocrit, hemoglobin, and total hemoglobin to levels above normal levels in adult rabbits, which indicates that the regulation of erythropoiesis in this age period is not geared to the same level and is not as accurate as in later life. Factors other than ESF may also participate in the regulation. When hypoxia was induced in iron-supplemented rabbits, RCV per kilogram further increased. The present data indicate that the "early anemia" in rabbits is iron responsive, and that the rate-limiting factor in erythropoiesis in this period is nutritional and not the erythropoietic system of regulation and production.
\end{abstract}

\section{Speculation}

Nutritional factors are essential in the development of the "early anemia" in rabbits. Erythropoietin levels are not increased, however, and weight increase is not impaired by the low hemoglobin levels, which suggests that other mechanisms compensate for the "anemia." In rabbits with essential nutrients in high concentrations, erythropoiesis may, on the other hand, proceed at a rate sufficient to maintain hemoglobin at adult levels even during suckling, thus making compensatory mechanisms unnecessary. This suggests that the "anemia" of the suckling rabbit is physiologic in the sense that adequate amounts of oxygen are transported to the tissues, although it traditionally is considered to be pathologic because it responds to iron supplementation. The "early anemia" illustrates the great potential of the growing organism to function adequately under a wide variety of conditions.

\section{Introduction}

There are conflicting data and theories in regard to the regulation of erythropoiesis during the first months of life. In almost all mammals a postnatal drop in hemoglobin occurs. The cause of this physiologic or "early anemia" is unknown. The theories put forward to explain the early anemia may be grouped in three categories. (1) The early anemia is due to age-specific changes in the erythrocytes, particularly increases in intracellular phosphates, which change the oxyhemoglobin dissociation curve and facilitate tissue oxygenation. It is well documented in several species that such 
changes occur during the first months of life $[1,6,20]$, but because such changes occur in almost all types of anemia [13], they may be compensatory mechanisms. (2) The "early anemia" is due to unresponsiveness of the $\mathrm{O}_{2}$-registering organ(s), to incapacity of the ESFproducing organ(s), or to incapacity of the bone marrow to produce erythrocytes, particularly during the transition from hepatic to myeloid erythropoiesis. In most species ESF is produced as a response to hypoxia also in this period [7], but the data conflict in regard to the quantitative aspects. Several studies indicate, however, that factors other than ESF govern erythropoiesis in this age group [21]. Rats do not increase erythropoiesis as a response to hypoxia or exogenous ESF, and the supression of erythropoiesis after blood transfusion, starvation, or nephrectomy is less pronounced than in adult animals [21]. (3) The "early anemia" is due to environmental, particularly nutritional factors. This hypothesis was previously favored but has received less attention lately.

The present studies were performed to investigate the two latter theories. The ESF production after hypoxia, the production of erythrocytes after hypoxic stimuli, and the role of iron in the erythropoietic response to hypoxia were studied during the suckling period. The rabbit was chosen as a model because of its size, and because it has a definite "early anemia" with a clear cut end point [15].

\section{Material and Methods}

Albino rabbits were used throughout the study. The pregnant rabbits were received at least 1 week before term. They were fed pellets for rabbits containing 12.5 $\mathrm{mg}$ iron $/ 100 \mathrm{~g}$ pellet and ate approximately $150 \mathrm{~g}$ pelletes $/ 24 \mathrm{hr}$. The rabbits were weaned between 20 and 25 days of age.

Blood samples were withdrawn from ear veins. Heart punctures were performed as bleeding procedure and to sample blood for erythropoietin assays. The blood was heparinized, centrifuged, and plasma was frozen at $-20^{\circ}$ until injected into exhypoxic, polycythemic mice for ESF determination. Randomized, female mice of the NMRI/BOM strain which weighed between 25 and $32 \mathrm{~g}$ were used for the bioassay. The mice were exposed to intermittent hypoxia for 3 weeks. Plasma or $\mathrm{NaCl}$ solution in doses of $0.5 \mathrm{ml}$ were injected on days 4 and 5 out of chamber, $0.5 \mu \mathrm{Ci}{ }^{59} \mathrm{Fe}$ was injected on day 6, and the 72-hr uptake in erythrocytes was used as a variable. Groups of mice injected with saline and with an internal laboratory standard of erythropoietin were used as control subjects.

Hemoglobin was determined by the cyanmethemoglobin method. The erythrocytes were determined in an automatic cell counter. Hematocrit was determined in microhematocrit tubes. Reticulocytes were stained with brilliant cresyl blue and 2000 erythrocytes were counted. The method for making the reticulocyte smears was essential. With ordinary smear technique with a spreading slide the difference between areas in the beginning and at the end of the smear was of the magnitude $1 / 2$. With the cover slip method the reticulocytes were evenly distributed. Erythrocyte volume was determined with the ${ }^{51} \mathrm{Cr}$ method [11] at 20 days of age and in adult rabbits.

To study the effect of hypoxia on ESF production, the rabbits were placed in a low pressure chamber and exposed to $0.5 \mathrm{~atm}$ for $6 \mathrm{hr}$. Immediately after the hypoxic period blood was withdrawn by heart puncture. Blood from the youngest rabbits was pooled, all samples were centrifuged, and the plasma was pipetted off and frozen at $-20^{\circ}$ until used.

The effect of hypoxia on erythropoiesis was studied by placing the rabbits in the low pressure chamber at $0.5 \mathrm{~atm}$ for $6 \mathrm{hr} / 24 \mathrm{hr}$ from day 10-day 19. At day 20 RCV was measured.

The effect of bleeding on ESF production was studied in rabbits bled by heart puncture on days 10 and 18. Eighteen hours later blood was again withdrawn for ESF assay as described above. The effect of bleeding on erythropoiesis was studied by withdrawal of about $25 \%$ of the blood volume from rabbits on days 10-12, by checking hematocrit and reticulocytes and by measurement of RGV at day 20.

Iron sorbitol [22] was given i.m. every 3rd day from day 10-day 19 in doses of $0.2 \mathrm{ml}$ which supplied $10 \mathrm{mg}$ $\mathrm{Fe}^{++++} /$dose.

Urine was collected for ESF determination by bladder puncture at autopsy from 10 rabbits which died in the first 2 days.

\section{Results}

Table I shows the hematocrit, hemoglobin, and mean corpuscular hemoglobin concentration in rabbits with and without iron supplement. In the control group the hematocrit and hemoglobin dropped to the lowest value at 20-25 days of age. This coincided with the end of the suckling period. After weaning, hemoglobin and hematocrit rose to adult levels within 10-14 days. 
Table I. Hematocrit $(\mathrm{Ht}$ ), hemoglobin (H.b), and mean corpuscular hemoglobin concentration (MCHC) in 8 rabbits supplemented with iron sorbitol from the 10 th to the 19 th day of life and in 16 unsupplemented control rabbits ${ }^{1}$

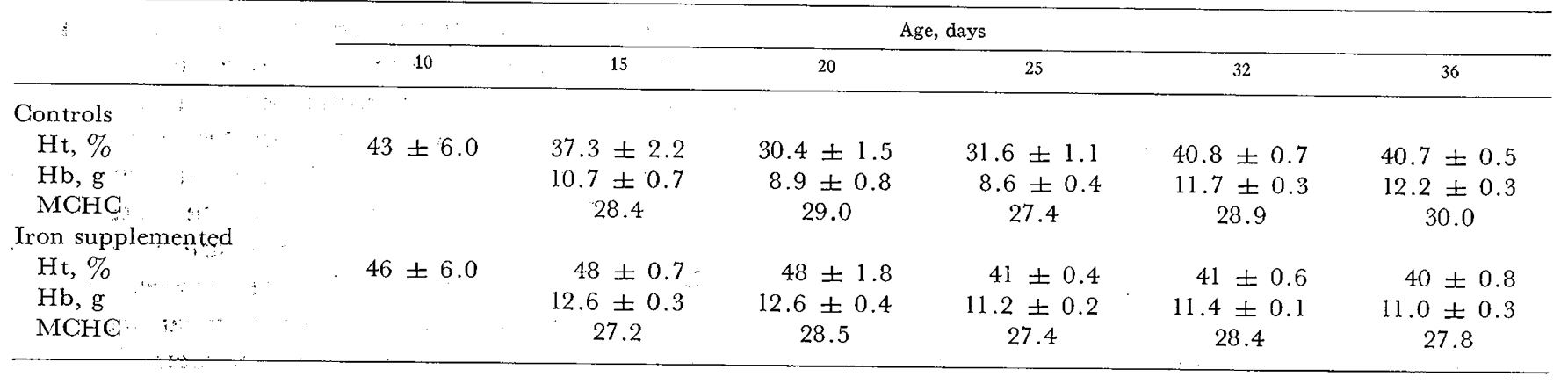

Table II. Increase in weight and erythrocyte volume (RCV) between 10 and 20 days of age in rabbits with and without supplementation of iron and with and without exposure to hypoxia ${ }^{1}$

\begin{tabular}{|c|c|c|c|c|c|c|c|c|c|}
\hline \multirow{2}{*}{$\begin{array}{c}\quad \\
\text { Experimental subject }{ }^{2} \\
\vdots \quad\end{array}$} & \multicolumn{3}{|c|}{10 Days of age } & \multicolumn{3}{|c|}{20 Days of age } & \multicolumn{3}{|c|}{ Increase between 10 and 20 days } \\
\hline & Weight, $g$ & $\mathrm{BV}, \mathrm{ml}$ & $\mathrm{RCV}$ & Weight, $g$ & $\mathrm{Hb}, \mathrm{g}$ & $\mathrm{RCV}, \mathrm{ml}$ & Weight, $g$ & $\mathrm{RCV}, \mathrm{ml}$ & $\begin{array}{c}\mathrm{RCV} / 100 \mathrm{~g} \\
\text { weight increase }\end{array}$ \\
\hline \multicolumn{10}{|l|}{$\begin{array}{l}\text { No hypoxia } \\
\text { Iron suppl }\end{array}$} \\
\hline 16.2 & 225 & 15.2 & 6.2 & 385 & 13.1 & 11.2 & 160 & 5.0 & 3.1 \\
\hline 16.4 & 165 & 11.2 & 5.0 & 325 & 12.8 & 11.4 & 160 & 6.4 & 4.0 \\
\hline 17.1 & 292 & 19.8 & 9.1 & 605 & 11.7 & 16.7 & 313 & 7.6 & 2.4 \\
\hline 17.2 & 205 & 14.0 & 6.7 & 475 & 11.6 & 11.4 & 270 & 4.7 & 1.7 \\
\hline 18.4 & 116 & 7.9 & 4.0 & 300 & 12.0 & 10.6 & 184 & 6.6 & 3.6 \\
\hline 18.6 & 150 & 10.2 & 5.1 & 330 & 14.5 & 12.2 & 180 & 7.1 & 3.9 \\
\hline 18.7 & 112 & 7.6 & 3.4 & 272 & 11.9 & 10.2 & 160 & 6.8 & 4.2 \\
\hline 18.9 & 146 & 9.8 & 4.7 & 316 & 12.8 & 11.9 & 170 & 7.2 & 4.2 \\
\hline Mean & $176 \pm 23$ & $12.0 \pm 1.6$ & $5.5 \pm 0.7$ & $376 \pm 47$ & $12.6 \pm 0.4$ & $12.0 \pm 0.8$ & $200 \pm 22$ & $6.4 \pm 0.4$ & $3.4 \pm 0.3$ \\
\hline Controls (14) & $201 \pm 11.7$ & $13.6 \pm 0.8$ & $6.4 \pm 0.4$ & $403 \pm 25$ & $8.9 \pm 0.8$ & $7.5 \pm 0.4$ & $203 \pm 9$ & $1.1 \pm 0.5$ & $0.54 \pm 0.5$ \\
\hline $\begin{array}{l}\text { Hypoxia } \\
\text { Iron supplement, } \mathrm{g}\end{array}$ & & & & & & & & & \\
\hline 18.1 & 127 & 8.6 & 4.8 & 275 & 14.4 & 11.5 & 148 & 6.7 & 4.6 \\
\hline 18.5 & 141 & 9.6 & 5.0 & 270 & 12.0 & 10.3 & 131 & 5.3 & 4.0 \\
\hline 18.8 & 158 & 10.7 & 5.8 & 258 & 13.3 & 11.5 & 100 & 5.7 & 5.7 \\
\hline Mean & $142 \pm 9$ & $9.6 \pm 0.6$ & $5.2 \pm 0.3$ & $267 \pm 5$ & $13.2 \pm 0.7$ & $11.1 \pm 0.4$ & $126 \pm 20$ & $5.9 \pm 0.4$ & $4.8 \pm 0.8$ \\
\hline Controls (8) & $187 \pm 11$ & $12.7 \pm 0.7$ & $6.1 \pm 0.3$ & $372 \pm 23$ & $8.6 \pm 0.9$ & $8.5 \pm 0.4$ & $185 \pm 16$ & $2.4 \pm 0.9$ & $1.3 \pm 0.9$ \\
\hline
\end{tabular}

${ }^{1} \mathrm{BV}$ : blood volume; $\mathrm{Hb}$ : hemoglobin.

2 Number of subjects is shown in parentheses.

At 36 days of age hemoglobin in the iron-supplemented group was slightly lower than in the control group.

Iron supplement completely alleviated the fall in hemoglobin and hematocrit. The hematocrit at 20 days of age in the iron-supplemented group was significantly higher even than in adult rabbits whereas hemoglobin was moderately increased above adult levels. Figure 3 (controls) shows that the increased hemoglobin and hematocrit in the iron-treated rabbits were due to an increase of total erythrocyte volume and not due to hemoconcentration. Erythrocyte volume per kilogram increased to levels also significantly above the levels in adult rabbits [11]. Mean corpuscular hemoglobin concentration increased slightly in the control group but stayed the same in the iron-supplemented group.
Table II shows the weight increase in the individual, iron-supplemented rabbit compared with the mean of the controls. The blood volume at 10 days of age is calculated assuming that it is $6.8 \%$ of body weight. This figure is arrived at from our own data at 20 days of age when the blood volume was $6 \%$ of body weight and from Mott's data which indicates that the blood volume in the 2nd week is about $0.8 \%$ higher than in the 4 th week [19]. The erythrocyte volume is then calculated using the actual hematocrit of the individual rabbit. Finally, the increase between 10 and 20 days in weight, $\mathrm{RCV}$, and $\mathrm{RCV} / 100 \mathrm{~g}$ weight increase is outlined.

These data indicate that there is a $15 \%$ net increase in RCV in unsupplemented rabbits, whereas ironsupplemented rabbits double $\mathrm{RCV}$ in this period. The 
net increase in $\mathrm{RCV} / 100 \mathrm{~g}$ weight increase after iron supplementation is sufficient to maintain high hematocrit levels even in very rapidly growing animals. The mean total hemoglobin at 20 days of age after iron supplementation is $8.9 \mathrm{~g} / \mathrm{kg}$ which is higher than in the control rabbits $(5.3 \mathrm{~g} / \mathrm{kg})$, higher than in adult rabbits $(6.9 \mathrm{~g} / \mathrm{kg})$, and of the same magnitude as Mott found for rabbits during the first days of life $(8.2-9.7 \mathrm{~g} / \mathrm{kg})$.

In Figure 1 is depicted the levels of erythropoietin in plasma in control rabbits during the first 70 days of life. The data are cross-sectional. There was no spontaneous elevation of the ESF values during the suckling period. At the time of weaning, there was, however, a marked increase in ESF values, which corresponds well with the rise in hemoglobin and hematocrit after weaning. There was no relation between rise in ESF levels and hemoglobin in the small number of rabbits with elevated ESF.

Figure 2 depicts the plasma ESF values in plasma after a hypoxic period of $6 \mathrm{hr}$ in $0.5 \mathrm{~atm}$ in young rabbits compared with adult rabbits. In newborn rabbits there was no increase in ESF after hypoxia, whereas during the rest of the suckling period the ESF levels in plasma after hypoxia were increased, and the increase was comparable with that in adult rabbits.

Table III shows the erythropoietin production after bleeding at day 10 and day 18. As is seen in Figure 1, there was no spontaneous rise in plasma ESF levels at day 10, whereas the levels in plasma were increased after bleeding. At day 18 there was some increase in

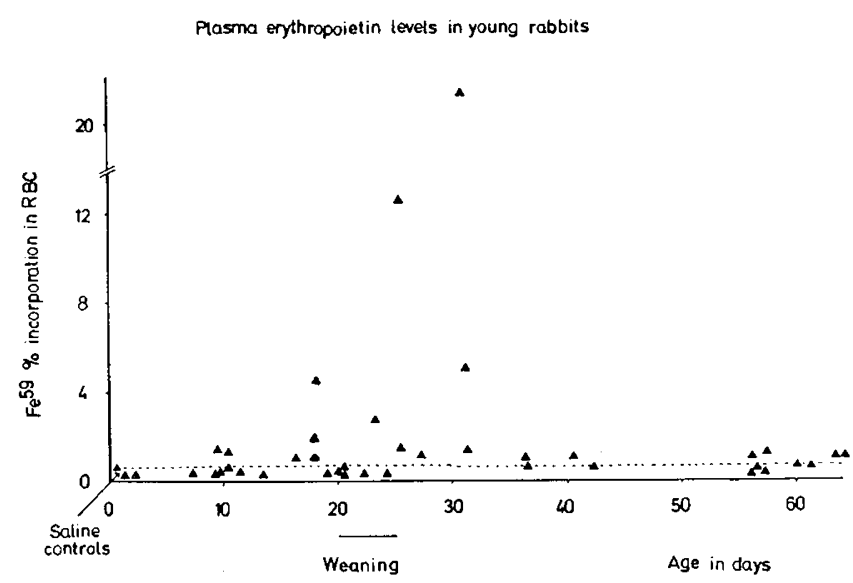

Fig. 1. Plasma erythropoietin levels in normal, untreated rabbits during the first 70 days of life expressed as the ${ }^{50} \mathrm{Fe}$ incorporation in erythrocytes $(R B C)$ of polycythemic mice. The number of mice in each assay varied from two to six depending upon the amount of plasma available. - - : mean uptake of ${ }^{59} \mathrm{Fe}$ in salineinjected control mice.

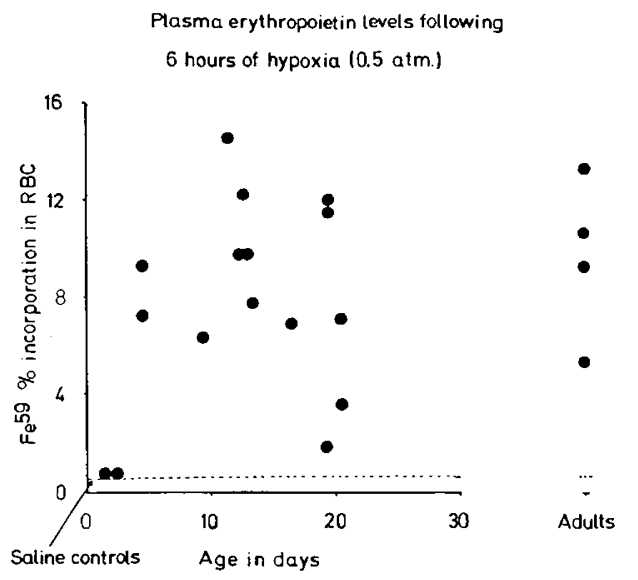

Fig. 2. Plasma exythropoietin levels in young and adult rabbits immediately after a period of $6 \mathrm{hr}$ of hypoxia. The number of mice in each assay varied between two and six. $R B C$ : erythrocytes.

Table III. Erythropoietin (ESF) levels in plasma $18 \mathrm{hr}$ after bleeding 1

\begin{tabular}{|c|c|c|c|c|c|c|}
\hline \multirow{2}{*}{ Rabbit } & \multirow{2}{*}{$\begin{array}{l}\text { Age, } \\
\text { days }\end{array}$} & \multirow{2}{*}{$\begin{array}{c}\text { Amount } \\
\text { of blood } \\
\text { with- } \\
\text { drawn, } \\
\% \mathrm{HV}\end{array}$} & \multicolumn{2}{|c|}{$\begin{array}{l}\text { Values before } \\
\text { bleeding }\end{array}$} & \multicolumn{2}{|c|}{$\begin{array}{l}\text { Values } 18 \mathrm{hr} \text { after } \\
\text { bleeding }\end{array}$} \\
\hline & & & $\mathrm{Ht}, \%$ & $\begin{array}{l}\text { Plasma ESF, } \\
\text { 59Fe uptake }\end{array}$ & $\mathrm{Ht}, \%$ & $\begin{array}{l}\text { Plasma ESF, } \\
{ }^{59} \mathrm{Fe} \text { uptake }\end{array}$ \\
\hline $26 / 4$ & 10 & 30 & 35 & & 30 & $13.77 \pm 3.50$ \\
\hline $26 / 5$ & 10 & 20 & 35 & & 30 & $4.75 \pm 0.06$ \\
\hline $26 / 7$ & 10 & 30 & 34 & & 30 & $4.92 \pm 1.30$ \\
\hline $27 / 6$ & 18 & 35 & 25 & $4.34 \pm 0.79$ & 20 & $14.24 \pm 2.40$ \\
\hline $27 / 7$ & 18 & 17 & 27 & $1.68 \pm 0.10$ & 19 & $11.02 \pm 1.68$ \\
\hline $27 / 8$ & 18 & 25 & 22 & $2.17 \pm 0.31$ & 21 & $9.40 \pm 0.74$ \\
\hline
\end{tabular}

${ }^{1} \mathrm{HV}$ : hemoglobin volume; $\mathrm{Ht}$ : hematocrit.

plasma ESF levels before bleeding and a more marked increase $18 \mathrm{hr}$ after bleeding. In rabbits bled at the age of 10-12 days, there was no increase in reticulocytes. The hematocrit fell lower than in weight-matched controls and the anemia lasted longer. Erythrocyte volume per kilogram in two bled rabbits at 20 days of age was slightly below RCV per kilogram in the controls, which indicates that the rabbits had reproduced some, but not all, of the lost erythrocytes.

Figure 3 illustrates the effect of intermittent hypoxia from day 10-day 19 on the total erythrocyte volume measured at day 20 in rabbits with and without iron supplement. In rabbits without iron supplement there was a slight but nonsignificant increase of RCV per kilogram after hypoxia when the total group was compared with the control group. As is shown in Table IV, however, there was a significant difference in RCV per kilogram when weight-matched pairs from the two groups were compared. Figure 3 further shows that iron supplement increased RCV per kilogram signifi- 


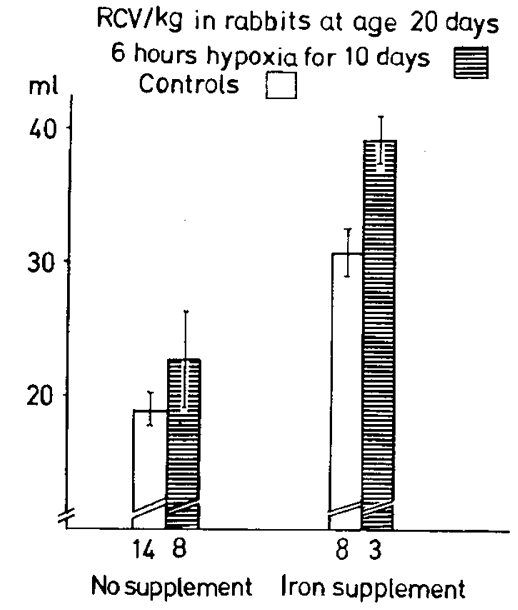

Fig. 3. Erythrocyte volume per kilogram body weight measured at day 20 in rabbits with and without iron supplement from day 10-day 19 and with and without exposure to hypoxia during the same period. SEM is depicted on the top of each column, and the number at the bottom of the column indicates the number of rabbits in each group. The difference between the iron-supplemented and unsupplemented control groups is significant at the $1 \%$ level and between the hypoxia-exposed, iron-supplemented group and the group receiving iron but no hypoxia at the $5 \%$ level.

cantly and when iron supplementation was administered in addition to induction of hypoxia, there was an increase in $\mathrm{RCV}$ per kilogram to levels significantly above the levels in iron-treated control rabbits and double as high as in rabbits not exposed to hypoxia and without iron supplement. Further data on the effect of intermittent hypoxia is given in Table II. The weight increase in these groups is lower than in rabbits not exposed to hypoxia. The total increase in $\mathrm{RCV}$ in the most rapidly growing, non-hypoxiaexposed rabbits was higher than in the hypoxia-exposed animals, whereas the increase per $100 \mathrm{~g}$ weight increase was lower. Both hypoxia and rapid growth may be considered as potent stimulus for erythropoiesis in this age group when sufficient amounts of essential nutrients are available. Between age 10 and 20 days the newborn rabbits are thus capable of increasing their exythrocyte production to such a degree that they have a RCV twice as large as in the untreated control rabbits.

Urine from 2-day-old rabbits increased ${ }^{59} \mathrm{Fe}$ uptake in erythrocytes of polycythemic mice, which indicates that ESF also is produced and excreted in urine in this age period.

\section{Discussion}

The present data in rabbits which demonstrate low hematocrit and hemoglobin levels in the 3rd week of life, often termed "early anemia," are in accordance with the findings of Mc Cance and Widdowson [18], Mott [19], and Laird et al. [15]. As in other species, the "early anemia" develops during the suckling period, and the hemoglobin levels are lowest at the end of this period. After weaning there is a rapid increase in hemoglobin to adult levels. Growth velocity is an important factor in the development of the "anemia;" the lowest hemoglobin levels occur in the most rapidly growing animals [11]. This could point to an incapacity of the regulatory system or of the liver and bone marrow to produce erythrocytes, particularly during the transition from hepatic to myeloid erythropoiesis, which occurs between days 5 and 15 in rabbits [16]. The data in the present study exclude these possibilities as explanations for the "early anemia" in rabbits.

The plasma ESF levels in the newborn rabbits are not elevated spontaneously until the time of weaning, even though there is a marked decline in hemoglobin before this time. This may indicate either that the tissues are well oxygenated, or that the regulatory system of erythropoiesis is unresponsive. Levels of ESF in plasma rose as in adult rabbits, however, both after bleeding and hypoxia, which suggests that the ESF production is normal. The lack of spontaneous increase in ESF on declining hemoglobin levels before weaning suggests that compensatory mechanisms are in operation. Riegel and Ruhrmann [20] found increased $\mathrm{P}_{50}$ between the 13 th and 27 th day in rabbits, which indicates that compensatory mechanisms, probably increased intraerythrocytic 2,3-diphosphoglycerate (2,3DPG) and ATP are operating in rabbits as in other species $[1,6]$ in this age period. This may explain why $\mathrm{ESF}$ is not elevated until a certain low level of hemo-

Table IV. Weight and erythrocyte volume (RCV) at 20 days of age in weight-matched pairs from the same litter ${ }^{1}$

\begin{tabular}{|c|c|c|c|c|c|}
\hline \multicolumn{2}{|c|}{ Controls } & \multicolumn{2}{|c|}{ Hypoxia-exposed } & \multicolumn{2}{|c|}{$\begin{array}{l}\text { Difference between hypoxia- } \\
\text { exposed and controls }\end{array}$} \\
\hline Weight, $g$ & $\mathrm{RCV}, \mathrm{ml}$ & Weight, $g$ & $\mathrm{RCV}, \mathrm{ml}$ & $\mathrm{RCV}$ & $\mathrm{RCV} / \mathrm{kg}$ \\
\hline 464 & 5.23 & 456 & 5.50 & 0.27 & 0.80 \\
\hline 338 & 8.30 & 306 & 8.38 & 0.08 & 2.84 \\
\hline 366 & 8.85 & 332 & 12.82 & 3.97 & 14.44 \\
\hline 407 & 8.39 & 428 & 12.29 & 3.90 & 8.10 \\
\hline 431 & 10.08 & 461 & 11.19 & 1.11 & 0.88 \\
\hline 364 & 7.48 & 316 & 6.68 & -0.80 & 0.60 \\
\hline 403 & 7.41 & 377 & 6.95 & -0.46 & 0.05 \\
\hline 398 & 7.96 & 382 & 9.12 & $1.16^{2}$ & $3.96^{2}$ \\
\hline
\end{tabular}

${ }^{1}$ One of the rabbits in the pair was exposed to hypoxia, the other served as control.

${ }^{2} 0.10>P>0.05$ 
globin is reached. This also corresponds to findings in children with iron deficiency anemia [12]. Since erythrocyte 2,3-DPG increases in most types of anemia including iron deficiency anemia [13], this does not mean that increased exythrocyte $2,3-\mathrm{DPG}$ is a primary agespecific change, it may be a secondary, compensatory phenomenon.

The rise of ESF levels at weaning and the following increase in erythropoiesis demonstrate a functioning regulatory system at this age. It could also point to a relation between the change in nutrition and the demand for oxygen carrying capacity because of changes in the oxyhemoglobin dissociation curve. Preliminary studies in this laboratory do not support the hypothesis, however, that the increased iron supply after weaning plays any role in this regard.

After hypoxia, the ESF levels in plasma in the suckling rabbits increased except for the first 2 days. Because the newborn animal tolerates hypoxia better than older animals [5], this may be the cause of the lack of plasma ESF increase in the first 2 days. The findings fit with the observation of Carmena et al. [4] that the ESF increase after hypoxia in 1-day-old rats was less than in adult rats. However, urine from newborn rabbits contained erythropoietin. Anemic hypoxia, introduced by bleeding at days 10 and 18 , also increased plasma ESF significantly. The present data thus indicate that the erythropoietin production after hypoxia is functioning in the suckling period as in adult rabbits, although one cannot exclude quantitative differences.

Previous studies in rats have indicated that the rate of erythropoiesis cannot be increased during the suckling period either by hypoxia $[2,8,17]$ or by exogenous ESF $[3,10]$. In bled rabbits this was apparently also the case, but based on the findings after iron loading, this was most likely due to iron unavailability. The present data show clearly that the rabbit can increase erythropoiesis to such a degree that RCV or RCV per kilogram at 20 days of age is doubled compared with normal control rabbits. When iron is given i.m. to suckling rabbits, the hematocrit, hemoglobin, RCV, and total hemaglobin are increased even above levels found in adult rabbits. This further underlines that the "early anemia" in rabbits is not caused by reduced capacity to produce erythrocytes. The data also suggest that the erythropoiesis in this age period is not as accurately regulated as in later life. Inasmuch as ESF was not elevated until weaning, the data further support previous conclusions [21] that erythropoiesis in the suckling period is governed by a different mechanism than that operating in adult animals and that factors in addition to erythropoietin regulated erythropoiesis.

Iron given i.m. in the same doses per kilogram body weight as in suckling rabbits did not increase erythropoiesis in adult rabbits. Any direct erythropoietic effect by the iron medication is therefore unlikely.

The "early anemia" in rabbits is thus iron responsive. Data published elsewhere indicate that considerable amounts of iron is present in the liver at the end of the suckling period [11]. The most likely explanation for the responsiveness to iron when iron is present in the depots is that iron is not mobilized rapidly enough for this high rate of erythropoiesis. Lack of iron in the bone marrow develops and the erythropoiesis becomes iron deficient [14]. The increased erythropoiesis after hypoxia also in the group not receiving iron indicates that more iron is made available when the demand is increased by hypoxia.

The erythropoietic response to hypoxia was, however, only marginal without iron supplement. After iron supplement the RCV per kilogram after hypoxia was significantly increased, but these rabbits gained less weight than the control rabbits. The present data indicate that rapid growth is just as potent stimulus for erythropoiesis as hypoxia. The marginal response to hypoxia in the suckling rabbit without iron supplement and the more marked response after iron indicate that it is nutritional factors which are rate limiting in this age period in the rabbit and not the erythropoietic system. A similar explanation, although alternative to that of the authors, could be offered for the findings in rats by Garcia and Van Dyke [10]. They found that there was a significant increase in erythropoiesis in hypertransfused suckling rats stimulated by erythropoietin, and concluded that in normal rats without transfusion, the animals were already maximally stimulated by erythropoietin and could not further respond unless hypertransfused. The finding might, however, be explained from the hypothesis of iron unavailability, because in transfused rats there will be large amounts of iron available for increased hemoglobin synthesis because of destruction of transfused cells.

As in other species [21], hypochromic macrocytes are produced in rabbits in the first weeks of life. The size of the cells reach adult levels after 60 days of life [20]. This also corresponds with the calculated mean cell volume from the data of Laird et al. [15]. Inasmuch as, in order to limit blood loss, determination of erythrocyte numbers was not part of our original study, the data cannot give answer to the question of whether iron supplementation alters the age-specific re- 
duction in cell size. The mean corpuscular hemoglobin concentration in iron-supplemented rabbits was not significantly different from the control rabbits in our study, but mean corpuscular hemoglobin concentration in the iron-treated group did not show the same increase as in the controls and as can be calculated from the previously mentioned studies [15, 20]. Our data thus suggest that iron supplementation does not influence the hypochromia of the macrocytes in newborn rabbits. This finding is in accordance with observations by Stohlman [21].

The "early anemia" of many species is often termed physiologic. This may be true also in rabbits in the sense that adequate amounts of oxygen are transported to the tissues. Traditionally, one would, however, consider low hemoglobin levels as an anemia when they increase after iron supplementation. This may, however, be open to discussion in the rapidly growing organism because it may merely reflect the great potentials of a developing animal to function adequately under a wide variety of conditions.

\section{Summary}

Rabbits develop an "early anemia" with the lowest hemoglobin values at the end of the suckling period (20-25 days). A rapid increase in hemoglobin follows weaning. During the period of suckling there was no spontaneous increase in levels of erythropoietin in plasma. At weaning the levels of erythropoietin in plasma increased markedly in some rabbits and erythropoiesis increased in all. Erythropoietin was found in urine from newborn rabbits, but their plasma levels did not increase after hypoxia. During the rest of the suckling period erythropoietin levels in plasma increased both after hypoxia and after bleeding. Erythrocyte volume per kilogram increased slightly in rabbits exposed to hypoxia between 10 and 19 days of age. After intramuscular iron was administered, hematocrit, hemoglobin, and RCV per kilogram increased above adult levels. Rabbits which received iron and were exposed to hypoxia increased RCV per kilogram to levels 2 times higher than the untreated control subjects.

The "early anemia" in rabbits is iron responsive. The regulatory system of erythropoiesis is intact in this age period, but is not accurately geared to the same levels as in adults. Other factors than erythropoietin may also participate in the regulation. The erythrocyteproducing organs have large capacity to produce erythrocytes and are not rate limiting for erythropoiesis in suckling rabbits.

\section{References and Notes}

1. Blunt, M. H., Kitchen, J. L., Mayson, S. M., and Huisman, T. H. J.: Red cell 2,3-diphosphoglycerate and oxygen affinity in newborn goats and sheep. Proc. Soc. Exp. Biol. Med., 138: 800 (1971).

2. Carmena, A., Lucarelli, G., Carnevali, C., and Stohlman, F., JR.: Regulation of erythropoiesis. XIX. Effect of hypoxia on erythropoiesis in the newborn animal. Proc. Soc. Exp. Biol. Med., 121: 652 (1966).

3. Carmena, A., Howard, D., and Stohlman, F., JR.: Neonatal regulation of erythropoiesis. J. Clin. Invest., 46: 1043 (1967).

4. Carmena, A., Howard, D., And Stohlman, F., JR.: Regulation of erythropoiesis. XXII. Erythropoietin production in the newborn animal. Blood, 32: 376 (1968).

5. Dawes, G. S.: Foetal and Neonatal Physiology (Yearbook Medical Publisher, Chicago, 1968).

6. Delivoria-Papadopoulos, M., Poncevic, N. P., and Oski, F. A.: Postnatal changes in oxygen transport of term, premature, and sick infants: The role of red cell 2,3-diphosphoglycerate and adult hemoglobin. Pediat. Res., 5: 235 (1971).

7. Finne, P. H., and Halvorsen, S.: Regulation of erythropoiesis in the fetus and newborn. Arch. Dis. Childhood, 47:683 (1972).

8. Garcia, J. F.: Erythropoietic response to hypoxia as a function of age in the normal male rat. Amer. J. Physiol., 190: 25 (1957).

9. GARCIA, J. F.: Changes in blood, plasma and red cell volume in the male rat, as a function of age. Amer. J. Physiol., 190: 19 (1957).

10. Garcia, J. F., ANd VAN Dyke, D. C.: Response of rats of various ages to erythropoietin. Proc. Soc. Exp. Biol. Med., 106: 585 (1961).

11. Halvorsen, K., and Halvorsen, S.: The "early anemia," its relation to postnatal growth rate, milk feeding and iron availability: Experimental study in rabbits. Arch. Dis. Childhood, 48: 842 (1973).

12. Hammond, D., Shore, N., and Movassaghi, N.: Production, utilization and excretion of exythropoietin. I. Chronic anemias. II. Aplastic crisis. III. Erythropoietic effects of normal plasma. Ann. N. Y. Acad. Sci., 149: 516 (1968).

13. HJELM, M.: The content of 2,3-DPG and some other phosphocompounds in human erythrocytes from healthy adults and subjects with different types of anemia. Försvarsmedicin, 5: 219 (1969).

14. Jacobs, P, AND Finch, C. A.: Iron for erythropoiesis. Blood, 37: $220(1971)$.

15. Laird, C. W., Fox, R. R., Mrtchell, B. P., BlaU, E. M., ANd Schultz, H. S.: Effect of strain and age on some hematological parameters in the rabbit. J. Physiol., 218: 1613 (1970).

16. Leeson, C. R., ANd Cutrs, J. H.: The postnatal development of the rabbit liver. Biol. Neonate, 20: 404 (1972).

17. Lucarelli, G., Porcellini, A., Carnevali, C., Carmena, A., and Stohlman, F., JR.: Fetal and neonatal exythropoiesis. Ann. N. Y. Acad. Sci., 149: 544 (1968).

18. Mc Cance, R. A., And Wrddowson, E. M.: The metabolism of iron during suckling. J. Physiol., 112: 450 (1951).

19. Motr, J.: Haemorrhage as a test of the function of the cardiovascular system in rabbits of different ages. J. Physiol., 181: 728 (1965).

20. Rieget, K., and RuhrmanN, G.: Über die Atemgastransport- 
funktion des Blutes und die Erythropoese junger Kaninchen. Acta Haematol., 32: 129 (1964).

21. Stohlman, F., JR.: Fetal Erythropoiesis. In: A. S. Gordon, Regulation of Hematopoiesis, Vol. 1. Red Cell Production (Appleton-Century-Crofts, New York, 1970).

22. Jectofer, Astra, Södertalje, Sweden.
23. The present address of Dr. K. Halvorsen is: Pediatric Department, Akershus Central Hospital, Nordbyhagen, Norway.

24. Requests for reprints should be addressed to: K. HALvorsen, Pediatric Department, Akershus Central Hospital, Nordbyhagen, Norway.

25. Accepted for publication October 19, 1973. 